\title{
Comparative Study of Porosity and Pores Morphology of Unalloyed Iron Sintered in Furnace and Plasma Reactor
}

\author{
Henrique Cezar Pavanati*, Ana Maria Maliska, Aloisio Nelmo Klein, Joel Louis René Muzart \\ Departamento de Engenharia Mecânica - LabMat, Campus Universitário, \\ CP 476, 88040-970 Trindade, Florianópolis - SC, Brazil
}

Received: November 27, 2006; Revised: February 27, 2007

\begin{abstract}
Samples of unalloyed iron were sintered in the presence of an abnormal glow discharge using a confined anode-cathode configuration. The samples were placed on a holder acting as the discharge anode inside an AISI 1020 steel hollow cathode. Heating of the outer cathode was obtained by the bombardment of ions and energetic neutral particles. As a consequence of the confined geometry, the sample was efficiently heated mainly by radiation from the cathode. In order to evaluate the results of the sintering process by plasma, samples of unalloyed iron were also sintered in a resistive furnace using the same thermal cycle. The porosity, dimension and morphology of the pores were characterized by means of four basic parameters: area fraction, mean diameter, shape factor and elongation factor. The results show that the shape factor depends on the pore size, a characteristic that was not observed for elongation factor. For samples sintered in plasma reactor or conventional furnace, no significant difference in the porosity or in the pores morphology was observed.
\end{abstract}

Keywords: powder metallurgy, plasma sintering, furnace sintering, porosity, pores morphology

\section{Introduction}

The use of abnormal glow discharge to sinter metallic components is a recent technique developed by the LabMat research group, which is being introduced as an alternative route to produce metallic components ${ }^{1}$. The preliminary studies using this technique were carried out at the end of the last decade, when sintered components of stainless steel and unalloyed iron were successfully produced using different geometries ${ }^{2,3}$.One of those was the hollow cathode discharge, with the sample placed on a holder acting as the inner cathode. Results of this process were recently published ${ }^{4-6}$.Sintering was also successfully performed by using a similar geometry with an outer cathode of AISI 1020 steel, and in this case the sample to be sintered is the inner electrode and acts as the anode ${ }^{7,8}$. Using this geometry, referred as confined anode-cathode configuration, the surface of the sample is enriched by elements coming from the outer cathode. When the outer hollow cathode was constituted by AISI 430 stainless steel, superficial chromium enrichment of the iron sample was observed ${ }^{9}$. However, as this is a new technique, more studies are required to reach the technological level suitable for industrial implementation.

Most of the properties of sintered components are strongly related to the porosity, pores dimension and morphology. These characteristics can be used as an indicative parameter to evaluate and control the sintering cycle in which the components were subjected. The conventional sintering process in metallic materials occurs basically through two mechanisms of mass transport: collective and individual transport of atoms ${ }^{10}$.If no external load is applied on the component of unalloyed iron, during the sintering cycle, at a temperature around $1150{ }^{\circ} \mathrm{C}$, the collective mass transport is negligible. Also, considering that the vapor pressure of iron at sintering temperature $\left(2.8 \times 10^{-3} \mathrm{~Pa}\right.$ at $\left.1150^{\circ} \mathrm{C}\right)^{11}$, is relatively low, the individual mechanism of evaporation and condensation can be also considered negligible. Therefore, volume, surface and grain boundary diffusion are the mechanisms of individual transport of atoms, which control the sintering of unalloyed iron. Diffusion of vacancies inside the component i.e. self-diffusion of atoms in the inverse direction is proportional to the

*e-mail: pavanati@emc.ufsc.br

$\dagger$ In memoriam treatment temperature, resulting in the evolution of pores dimension and morphology.

The vacancies equilibrium concentration, near the surface, depends on the surface curvature. The higher is the surface curvature the higher is the equilibrium vacancies concentration in this region. This principle could be used to elucidate the porosity evolution mechanism during the sintering. The area in the vicinity of pores with higher curvatures presents higher vacancy concentration in equilibrium than the pores with lower curvatures. Spherical pores with different diameters would have different vacancies concentration in the vicinity of their surfaces (Figure 1a). These different vacancies concentration induces their diffusion in the direction of smaller to larger pores ${ }^{10}$. As a result of, the porosity tends to evolve during the sintering, as shown in the Figure 1a. The pores coalescence takes place from the larger to the smaller ones, considering that the flux of atoms occurs in the inverse direction of vacancy diffusion. In addition, the presence of different curvatures inside a same pore induces the diffusion of vacancies from higher to lower shape curvature of the pore, as shown in Figure $1 \mathrm{~b}$ and $1 \mathrm{c}$. Moreover, the vacancies diffusion for large pores will favor the mechanism in the Figure $1 \mathrm{~b}$ in detriment than that showed in Figure 1c. The distance between different curvatures of the irregularities in the same pore is smaller than the curvature of the pore geometry. Therefore, the evolution of pores to a spherical form (Figure 1) is essentially controlled by vacancies diffusion. Thus, the characterization of pore dimension and shape is a suitable procedure to evaluate the sintering rate of samples processed by means of different techniques.

In this work, samples of unalloyed iron were sintered using an abnormal glow discharge and resistive furnace following the same thermal cycle. An accurate metallographic preparation of sintered samples was carried out in order to perform a comparative quantification of porosity and pores morphology in both sintering processes. 


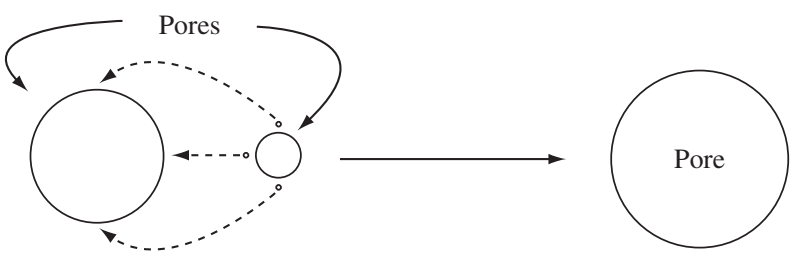

(a)

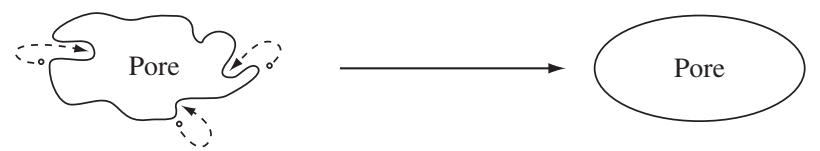

(b)

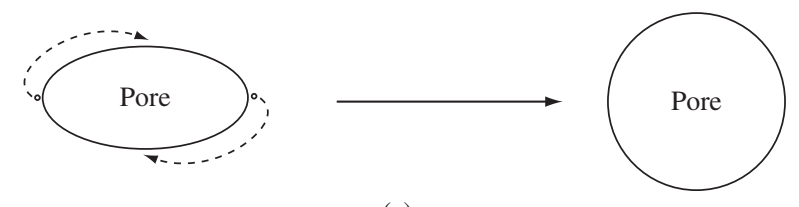

(c)

Figure 1. Mechanism of pores evolution during sintering. The dashed lines indicate vacancies diffusion.

\section{Experimental and Materials}

Samples, $9.5 \mathrm{~mm}$ in diameter and $6.0 \mathrm{~mm}$ in height, were produced with water atomized iron powder DC177 from Höganäs do Brasil Ltda. The powder was mixed with $0.6 \mathrm{wt}$. (\%) of zinc stearate and compacted to a pressure of $600 \mathrm{MPa}$ using a double action press with moving die body. The size of the powder particles ranged between 30 and $200 \mu \mathrm{m}$ and the mean particle size distribution was around $100 \mu \mathrm{m}$. After compaction, the green density was approximately $7.05 \times 10^{-6} \mathrm{~g} . \mathrm{m}^{-3}$. The compacted samples were sintered in a plasma reactor, described in detail elsewhere ${ }^{9}$, using the confined anodecathode configuration, Figure 2 . The cathode was negatively biased and the sample placed on the holder (50 $\mathrm{m}$ long and $10 \mathrm{~mm}$ in width) connected to the ground, then acting as the discharge anode. The outer cathode of cylindrical form, $60 \mathrm{~mm}$ long, $25 \mathrm{~mm}$ in diameter and $1 \mathrm{~mm}$ thick, was manufactured with AISI 1020 steel, composed basically of iron. In the plasma reactor, the temperature of the sample is function of the number and the energy of the ions impinging the cathode. Using a pulsed power source is possible to adjust the tension applied to the cathode (which is directly proportional to the energy of the ions) and the pulse length "time switched on" (correspondent to the effective time of bombardment). Raising these parameters the cathode temperature would also be raised. The pressure of the gas mixture into the reactor chamber is proportional to the number of ions impinging the cathode. Therefore, the temperature would be raised when the gas pressure is increased.

The delubing was carried out in the plasma reactor, using the procedure described by Santos and co-workers ${ }^{12}$. The hydrogen discharge was generated at a gas pressure inside the chamber of $400 \mathrm{~Pa}$ (3 Torr) using the anode-cathode configuration (Figure 2) and adjusting the gas flow to $3.33 \times 10^{-6} \mathrm{~m}^{3} \mathrm{~s}^{-1}(200 \mathrm{sccm}$ - standard cubic centimeter per minute). The cathode was biased at $500 \mathrm{~V}$ and the temperature, adjusted by varying the pulse length (time switched on) of the power source, was maintained at $350{ }^{\circ} \mathrm{C}$ for 30 minutes. After the delubing step, plasma sintering cycle took place in a gas mixture of $80 \% \mathrm{Ar}$ $+20 \% \mathrm{H}_{2}$, with output voltage of $500 \mathrm{~V}$. All samples were sintered at $1150{ }^{\circ} \mathrm{C}$ for 60 minutes, the pulse length of the power source and the gas flow, were fixed at $150 \mu \mathrm{s}$ and $4.0 \times 10^{-6} \mathrm{~m}^{3} \mathrm{~s}^{-1}(240 \mathrm{sccm})$, respectively. As mentioned above, the sintering temperature was reached increasing the pressure, i.e. the number of ions impinging the cathode. The pressure of the gas mixture in the chamber was

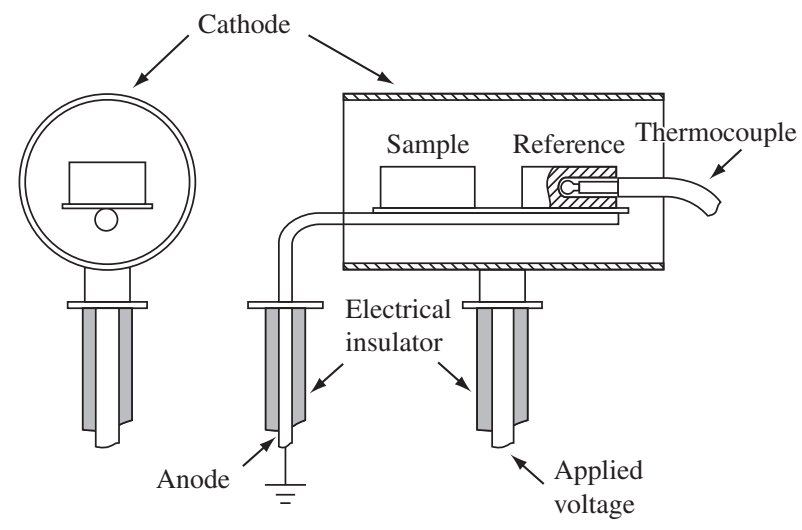

Figure 2. Schematic of the confined anode-cathode geometry.

measured using an Edwards capacitance manometer of $13300 \mathrm{~Pa}$ (100 Torr) full-scale. At the isothermal temperature of $1150{ }^{\circ} \mathrm{C}$, the gas pressure was approximately $1330 \mathrm{~Pa}$ (10 Torr). The furnace sintering was carried out using the same thermal cycle.

Six samples were sintered in both conditions of treatment: plasma reactor and conventional furnace. After sintering, the samples were longitudinally sectioned and impregnated with epoxy resin under vacuum, in order to minimize pores distortions during metallographic preparation. The metallographic procedure was carried out using an automatic polishing machine (Struers - TegraSystem 21), following the recommendations for low hardness porous materials. The images acquisition was carried out for non-etched samples using a digital camera coupled to an optical microscope (Leica - DM $4000 \mathrm{M}$ ), using 200x magnification, in gray scale, with resolution of $2088 \times 1550$ pixels, i.e. $574 \times 246 \mu \mathrm{m}^{2}$. For each sample a number of images were acquired ranging from 8 to 12 , in order to obtain higher than 3000 pores, as recommended for image analysis in reference 12. The image analysis software AnalySIS 2.11 (SIS-Software GmbH) was used to perform the quantitative analysis of the pores. Besides the area fraction of the pores, three other parameters were used to describe individually their dimension and morphology:

a) Pore diameter: $\mathrm{d}(\mu \mathrm{m})$;

b) Shape Factor: $\mathrm{f}_{\text {shape }}=(4 \pi \mathrm{A}) /\left(1.064 \mathrm{P}^{2}\right)$; and

c) Elongation Factor: $\mathrm{f}_{\text {elong }}=\left(\mathrm{d}_{\text {min }} / \mathrm{d}_{\text {max }}\right)$.

where, $\mathrm{A}$ is the pore area, $\mathrm{P}$ is the perimeter, the factor 1.064 corrects the perimeter for the effects produced by the digitization of the image $^{14}, \mathrm{~d}_{\text {min }}$ and $\mathrm{d}_{\max }$ are the minimum and maximum Feret diameters. The results obtained for shape factor $\left(\mathrm{f}_{\text {shape }}\right)$ and for elongation factor $\left(f_{\text {elong }}\right)$ whose value ranged between 0 and 1 , describe different characteristics, as illustrated in Figure 3. The shape factor depends not only on the geometrical form of the pore but also on the contour regularity of the pore as shown in Figure 3a. The shape factor is 1 for a smooth circumference. The elongation factor depicts the elongation level of the pores, independently of the contour, whose value is lower than 1 for elliptical form and equal to 1 for a circular form of the pore, as illustrated in Figure 3b. The porosity was obtained by calculating the area fraction of the pores related to the total area of the image. The results were an average value of 8 or more images, in order to attain a number of pores higher than 3000 . The pores were also discriminated with their average size. The quantification was carried out analyzing all the pores as well as only the larger ones. For the larger pores, it was taken into account the number of pores corresponding to $10 \%$ of the total number, i.e. only the $10 \%$ larger. The size and morphology were calculated taking the median value (50\% of cumulative frequency) of the frequency distribution for all pores and also for the $10 \%$ larger pores only in each sample. The results are an arithmetic average of six medians, values measured for each sample. 


\section{Results and Discussion}

The Figure 4 shows the non-etched images of samples sintered in conventional furnace (a) and plasma reactor (b) as an example. The corresponding cumulative frequency curves and frequency histograms, of pores diameter, elongation factor and shape factor are presented in Figure $5 \mathrm{a}$ and $\mathrm{b}$. It can be noted that most of the pores diameter values are around 5 to $7 \mu \mathrm{m}$ in the whole amplitude, which

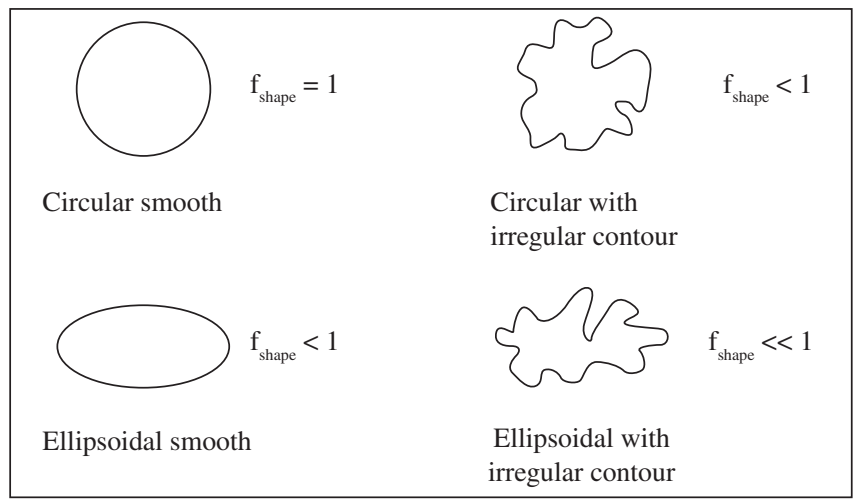

(a)

Ellipsoidal smooth

(b)

Figure 3. Values of a) $\mathrm{f}_{\text {shape }}$; and b) $\mathrm{f}_{\text {elong }}$ for different pores geometry.

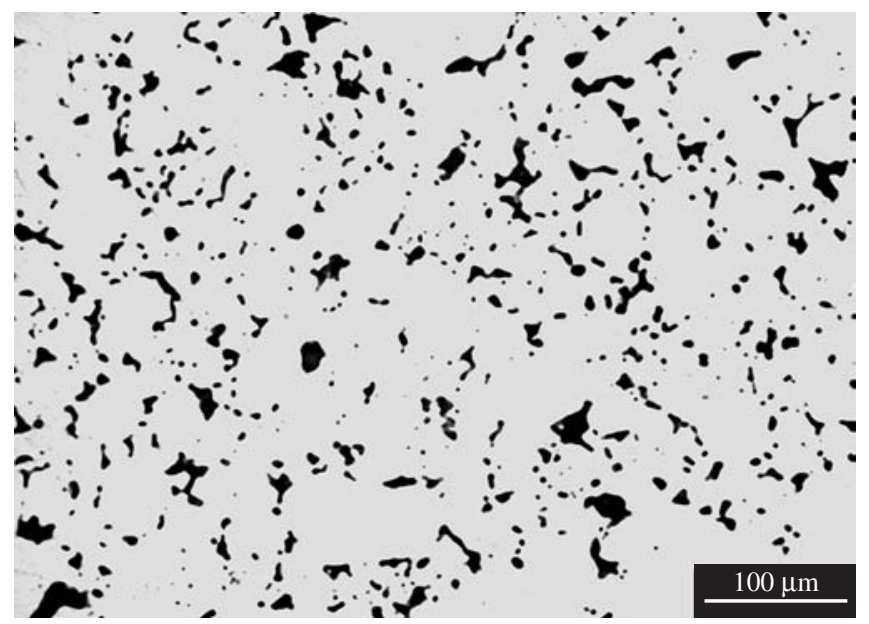

(a) ranged from 3 to $40 \mu \mathrm{m}$. It could be expected that this large amount of small pores influences strongly both $\mathrm{f}_{\text {shape }}$ and $\mathrm{f}_{\text {elong }}$ considering that small pores evolves easily to a circular form. For small pores, the mean distance that atoms need to diffuse from regions of higher curvature to lower one is smaller for than that for larger, thus favoring a fast rounding of the pores. However, the results presented in Figure 5, show a larger amount of $\mathrm{f}_{\text {elong }}$ around 0.7 and of $\mathrm{f}_{\text {shape }}$ approximately of 0.9 . As $\mathrm{f}_{\text {elong }}$ depict only how circular the form of the pore is, and $\mathrm{f}_{\text {shape }}$ include also how smooth the pore contour is, this indicates that in the sintering conditions used in this work, the evolution of pores to a smooth contour (Figure 1b) is more effective than to a circular form (Figure 1c). These observations are more clearly illustrated by the results presented in Figure 6, which shows the arithmetic average of the median values of the cumulative frequency function obtained for all pores and only for the larger pores for each sample. The median value of diameter is around 7 and $24 \mu \mathrm{m}$ for all and larger pores respectively. The value of $f_{\text {elong }}$, which is 0.68 for all pores decreases slightly to 0.64 when only the larger pores are considered. Then, even for a larger pore, where the distance that atoms need to diffuse in order to produce a circular form, is significantly larger than for small pore, the $f_{\text {elong }}$ factor is similar. Such an observation confirms that the mechanism of pore evolution depicted in Figure 1c is not effective. The $f_{\text {shape }}$ value of around 0.68 for all pores decreases strongly to 0.3 when only the $10 \%$ larger are considered. For small pores, the mean distance among irregularities inside a same pore is relatively short and so the diffusion of vacancies is easier from the regions of higher curvature to that with smaller one, favoring the fast pores smoothing.

The variation of $\mathrm{f}_{\text {shape }}$ values as a function of pores diameters are presented in Figure $7 \mathrm{a}$ and $\mathrm{b}$ for samples sintered in conventional furnace and DC-plasma reactor respectively. As well, the variation of $\mathrm{f}_{\text {elong }}$ values as a function of pores diameters are presented in Figure $8 \mathrm{a}$ and $\mathrm{b}$. Analyzing the Figure 7 is noted no relevant difference on the values of $\mathrm{f}_{\text {shape }}$ for the samples sintered in furnace or in DCplasma reactor. The same could be stated for the $f_{\text {elong }}$ factor for the furnace and DC-plasma reactor values (Figures 8a and b). Moreover, the $\mathrm{f}_{\text {elong }}$ factor does not show noticeable dependence on pore diameter, whereas the $f_{\text {shape }}$ factor significantly decreases for pore size augment. As the main pore morphology evolution mechanism is supposed to be the pore contour smoothing, which is preferred identified by the $f_{\text {shape }}$ parameter, it is believed that $f_{\text {shape }}$ is more suitable than $f_{\text {elong }}$ to estimate the evolution of pore morphology of sintered iron samples. These results are in good agreement with the conclusions of Marcu

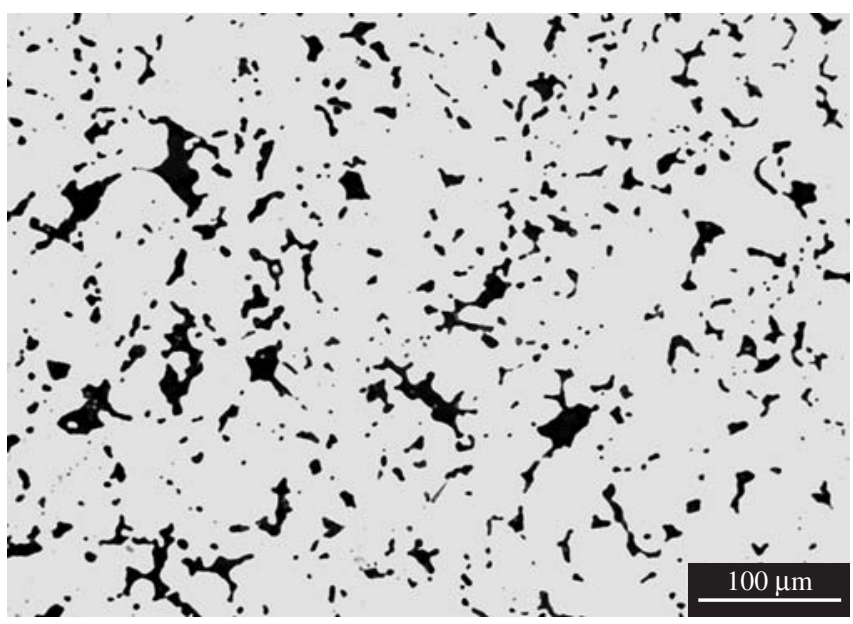

(b)

Figure 4. Micrographs of non-etched samples sintered in a) conventional furnace; and b) plasma reactor. 

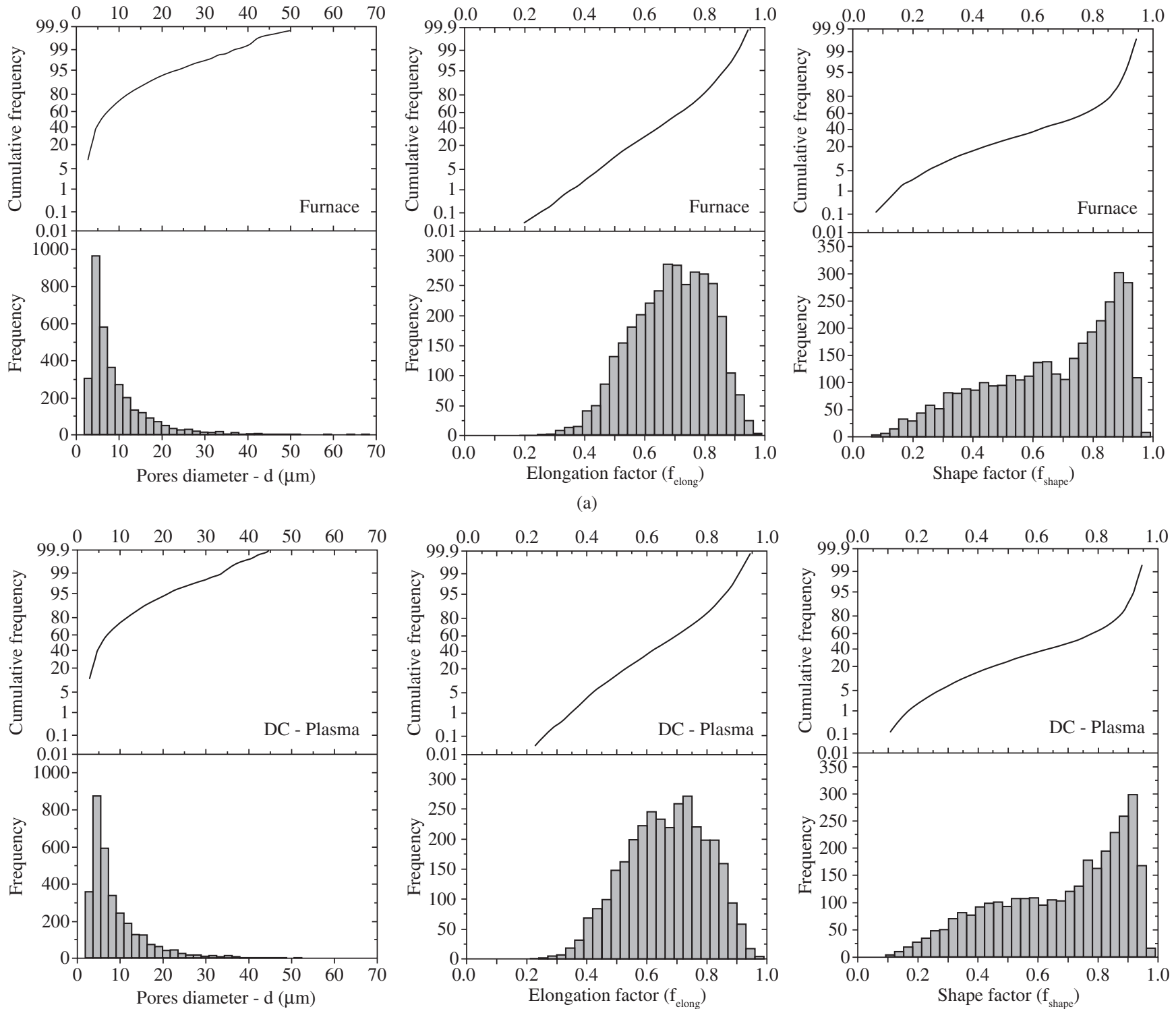

(b)

Figure 5. Frequency distribution and cumulative frequency function of the parameters $\mathrm{d}, \mathrm{f}_{\text {shape }}$ and $\mathrm{f}_{\text {elong }}$ of the samples sintered in a) conventional furnace; and b) plasma reactor.

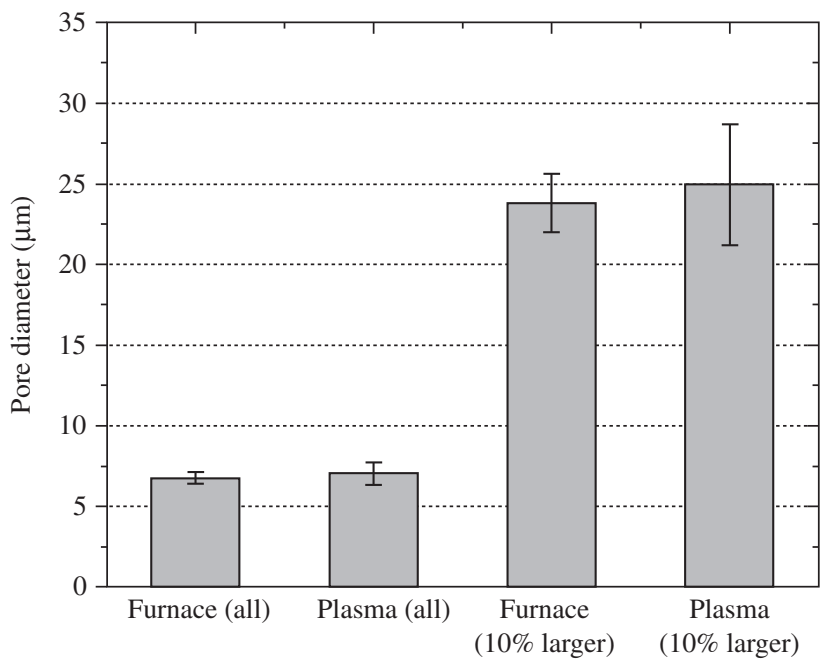

(a)

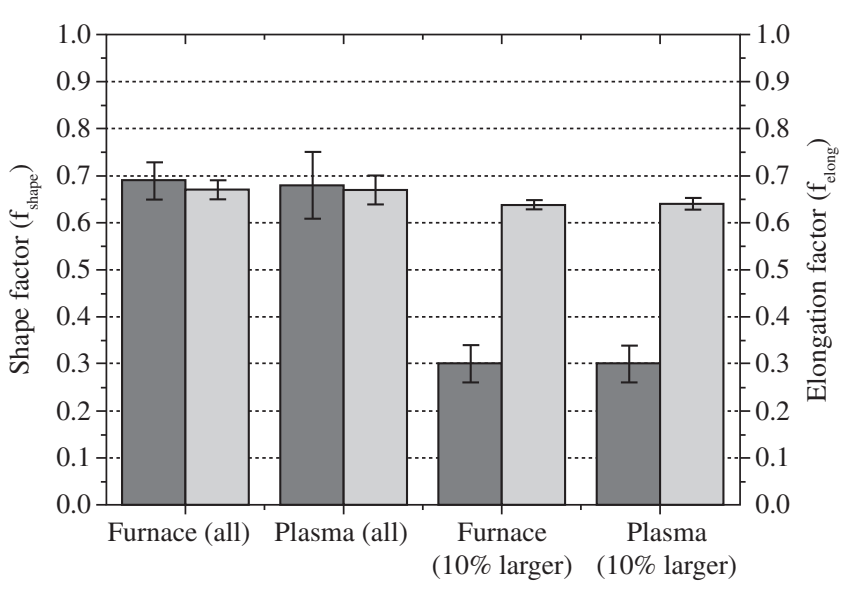

$\square$ Shape factor $\left(\mathrm{f}_{\text {shape }}\right) \quad \square$ Elongation factor $\left(\mathrm{f}_{\text {elong }}\right)$

(b)

Figure 6. Arithmetic average of the median values of a) pores diameter; and b) shape factor and elongation factor. 


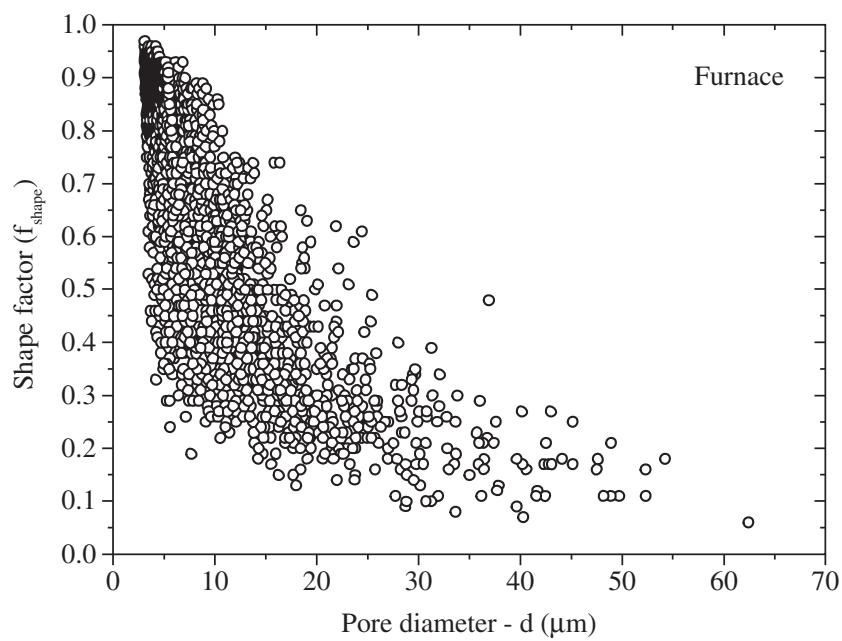

(a)

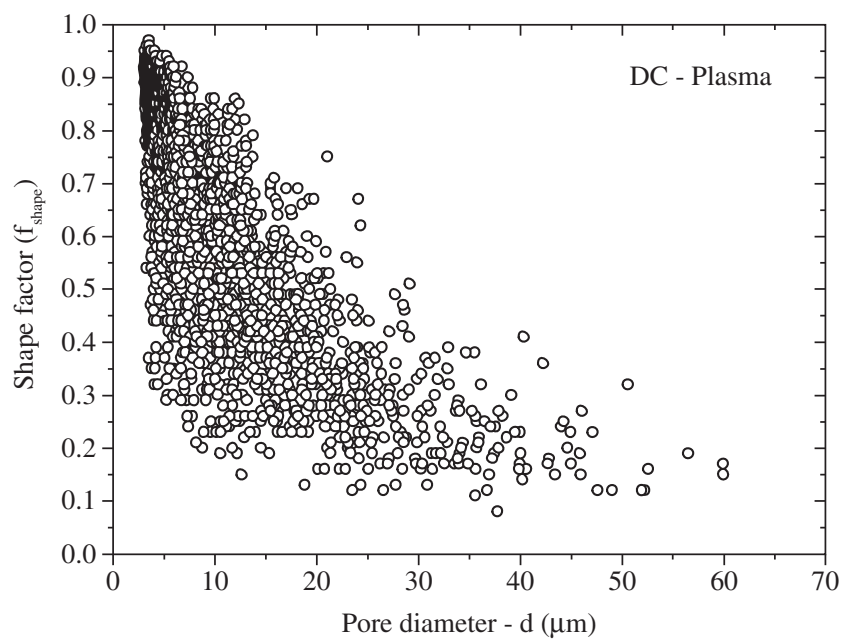

(b)

Figure 7. Shape factor as a function of pore diameter of samples sintered in a) furnace; and b) in DC-plasma reactor.

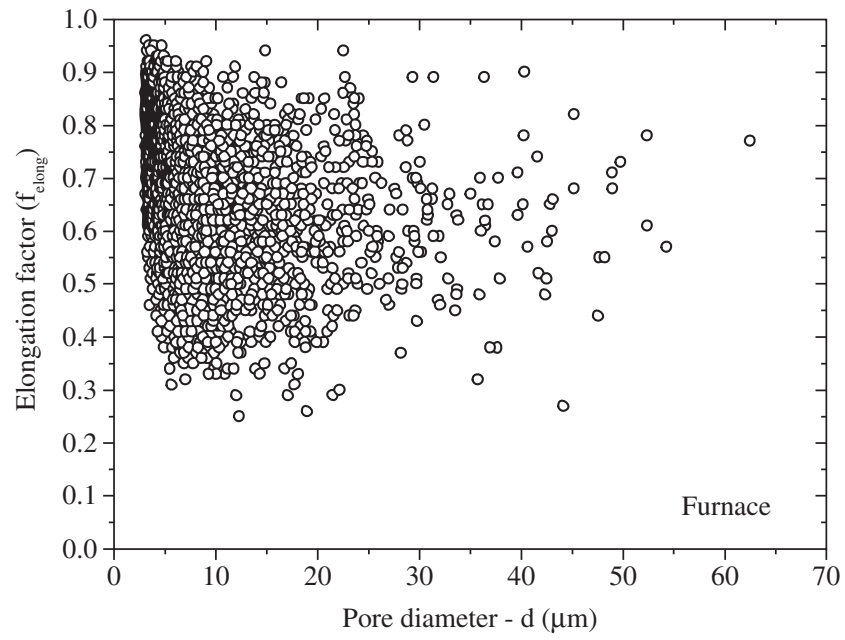

(a)

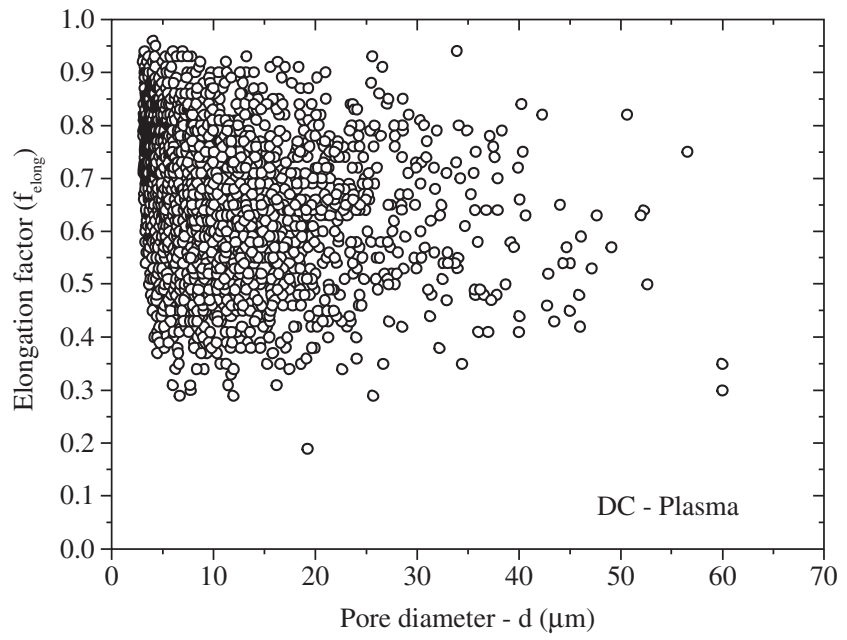

(b)

Figure 8. Elongation factor as a function of pore diameter of samples sintered in a) furnace; and b) DC-plasma reactor.

Puscas et al. ${ }^{14}$, who studied the effect of the process variable on the pores morphology evolution of sintered chromium steels. The referred authors ${ }^{14}$ was also observed that the $\mathrm{f}_{\text {shape }}$ is more efficient to study the pore morphology evolution. Another important observation of the results presented in Figure 5 and 6, is that microstructural parameters such as pore diameter, $\mathrm{f}_{\text {shape }}$ and $\mathrm{f}_{\text {elong }}$ are equal for samples sintered in conventional furnace or plasma reactor. Even for larger pores, which strongly influence the mechanical properties of sintered materials, the values of theses parameters are equal. The results presented in Table 1 show good agreement between the values of porosity, around $10 \%$ measured for samples sintered in conventional furnace and plasma reactor. In fact, the results of total porosity are not a strong evidence of the sintering efficiency of the process, considering that the compaction pressure of ductile metallic powder (as unalloyed iron) is the most important parameter with respect to final densification of the material ${ }^{14}$. As the porosity values presented in the Table 1 are coherent with densities of the green samples around $7.05 \times 10^{-6} \mathrm{~g} \cdot \mathrm{m}^{-3}$, which correspond to a porosity of approximately $10 \%$, it could be affirmed that the metallographic analysis is consistent. Then, it could be inferred that sintering of iron pieces in plasma reactor placed on the anode of a confined anode-cathode configuration, is similar to the process in conventional furnace.
Table 1. Porosity of samples sintered in conventional furnace and plasma reactor.

\begin{tabular}{ccc}
\hline & \multicolumn{2}{c}{ Porosity - area fraction $(\%)$} \\
\cline { 2 - 3 } Sample & Resistive furnace & DC-Plasma reactor \\
\hline 1 & 10.5 & 11.1 \\
2 & 11.1 & 10.2 \\
3 & 9.9 & 10.6 \\
4 & 10.7 & 9.7 \\
5 & 10.2 & 10.9 \\
6 & 9.8 & 10.4 \\
\hline Average value & 10.4 & 10.5 \\
Standard deviation & 0.5 & 0.5 \\
\hline
\end{tabular}

The morphologic map, which depicts the evolution of $f_{\text {elong }}$ as a function of $\mathrm{f}_{\text {shape }}$ for each pore, is presented in Figure $9 \mathrm{a}$ and $\mathrm{b}$ for samples sintered in conventional furnace and plasma reactor, respectively. Using the same methodology presented by Marcu Puscas and co-workers ${ }^{14}$, the dashed line represents the minimum limit of pore geometry, which is represented by $f_{\text {elong }}$. For a given $f_{\text {shape }}, f_{\text {elong }}$ may only be higher than the value corresponding to the equivalent smooth 


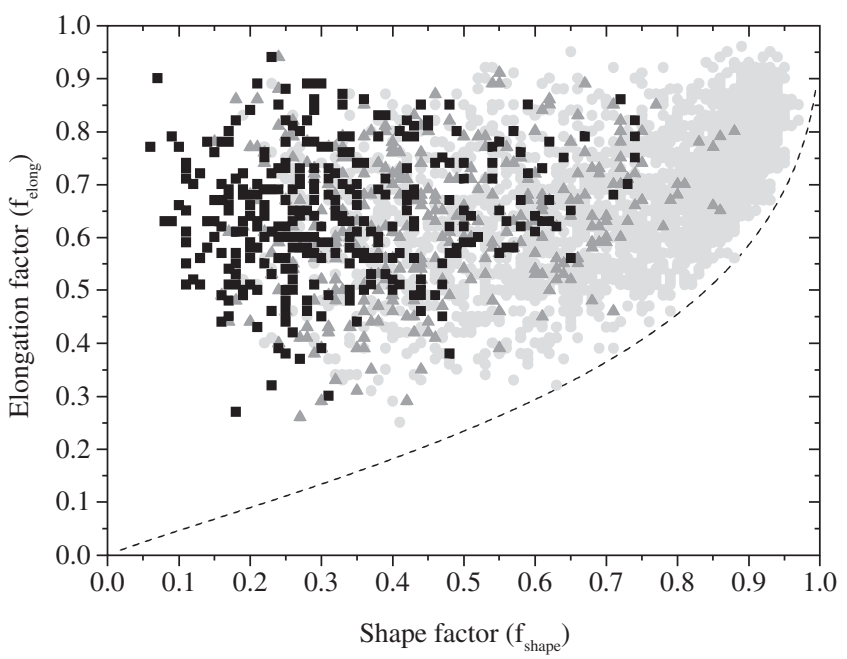

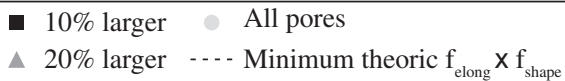

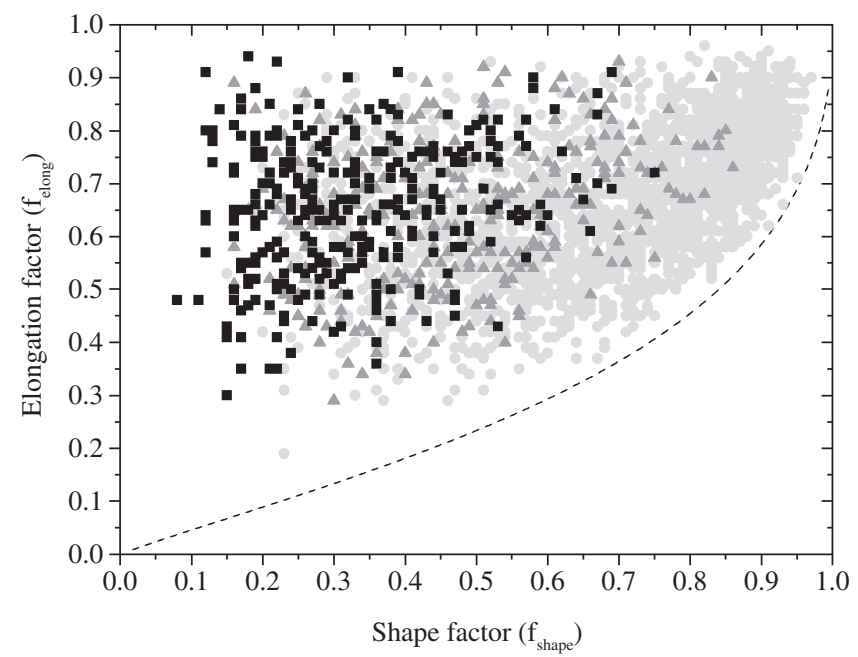

(b)

Figure 9. Morphological map i.e. elongation factor $v s$. shape factor of each measured pore of samples sintered in a) conventional furnace; and b) and plasma reactor.

ellipse, i.e. higher than the value pointed by the dashed line. All the experimental points fall in the upper part of the diagram both for samples sintered in conventional furnace or plasma reactor, which is in good agreement with the results predicted in reference 13. Similar behavior of the morphologic map for samples sintered in conventional furnace and plasma reactor can be observed. In addition, for a fixed $f_{\text {elong }}$, the larger the pore size the lower the $f_{\text {shape }}$ value. On the contrary, for a selected value of $f_{\text {shape }}$ no significant variation of $f_{\text {elong }}$ was observed. Such an effect is in good agreement with the results discussed earlier in this paper, i.e. that the shape factor seems to be more suitable than the elongation factor to evaluate the evolution of pore morphology during sintering.

\section{Conclusions}

Using the image analysis method, a comparative study of porosity, pores dimension and morphology of unalloyed iron samples sintered in conventional furnace and DC-Plasma reactor was performed. The application of mean diameter of the pores as well as the values of shape and elongation factor was appropriate to characterize the porosity and the individual dimension and morphology of the pores. In concordance with the literature, it was observed that the shape factor is the more suitable parameter to estimate the evolution of pores morphology during sintering. The measurements of porosity, using image analysis method was coherent with respect to density of the samples, suggesting that the metallographic preparation method, acquisition and images treatment were carried out accurately. Finally, the results of average values of porosity, shape and elongation factors show a good equivalence with respect to the sintering techniques used in this work, i.e. the microstructure analysis suggests that the thermal cycles (furnace and plasma) are equivalent. Then, it could be affirmed that the mechanical properties related to the porosity of components sintered in conventional furnace or plasma reactor should be similar.

\section{Acknowledgments}

This work was performed using funds from CAPES, FINEP/MCT, and $\mathrm{CNPq}$ research grants.

\section{References}

1. Klein AN et al, inventors. FEESC- Fundação de Ensino em Engenharia em Santa Catarina, assignee. Processo de sinterização de materiais metálicos por plasma. Brazilian Patent - INPI 9603488-2, 1996.

2. Muzart JLR, Batista VJ, Franco CV, Klein AN. Plasma sintering of AISI $316 \mathrm{~L}$ stainless steel: the influence of the processing cycle on the sample density. Advances in Powder Metallurgy and Particulate Materials. 1997; 3:77-84

3. Batista VJ, Binder R, Klein AN, Muzart JLR. Sintering iron in abnormal glow discharge. International Journal of Powder Metallurgy. 1998; 34(8):55-62.

4. Brunatto SF, Kühn I, Muzart JLR. Influence of the radial spacing between cathodes on the surface composition of iron samples sintered by hollow cathode electric discharge. Materials Research. 2001; 4(4):245-50.

5. Brunatto SF, Kühn I, Klein AN, Muzart JLR. Sintering iron using a hollow cathode discharge. Materials Science and Engineering A. 2003; 343(1-2):163-9.

6. Alves Jr C, Hajek V, dos Santos CA. Thermal behavior of supersolidus bronze powder compacts during heating by hollow cathode discharge. Materials Science and Engineering A. 2003; 348(1-2):84-9.

7. Maliska AM, Pavanati HC, Klein AN, Muzart JLR. The influence of ion energy bombardment on the surface porosity of plasma sintered iron. Materials Science and Engineering A. 2003; 352(1-2):273-8.

8. Lourenço JM, Maliska AM, Klein AN, Muzart JLR. Plasma sintering of unalloyed iron: a study of surface porosity. Materials Research. 2004;7(2):269-75.

9. Pavanati HC, Maliska AM, Klein, Muzart JLR. Sintering unalloyed iron in abnormal glow discharge with superficial chromium enrichment. Materials Science and Engineering A. 2005; 392(1-2):313-9.

10. German RM. Sintering theory and pratice. New York: J. Wiley \& Sons; 1996.

11. Gale WF, Totemeier TC. Smithells metals reference book, $8^{\text {th }}$ ed. Oxford: Butterworth Heinemann; 2004.

12. Santos MA, Maliska AM, Muzart JLR. Plasma dewaxing and sintering of compacted unalloyed iron. Materials Science Forum. 2003; 416(4): 329-34.

13. Metals Handbook, $9^{\text {th }}$ ed, vol. 7, Warrendale $(\mathrm{OH})$ : ASM International; 1984. 
14. Marcu Puscas T, Signorini M, Molinari A, Straffelini G. Image analysis investigation of the effect of the process variables on the porosity of sintered chromium steels. Materials Characterization. 2003; 50(1):1-10.
15. Tümmler F, Oberacker R. Introduction to Powder Metallurgy. Cambridge: The Institute of Materials; 1993. 
